\title{
Hanseníase: estigma e preconceito vivenciados por pacientes institucionalizados em Santa Catarina (1940-1960)
}

Leprosy: stigma and prejudice lived by institucionalized patients in Santa Catarina State, Brazil (1940-1960)

Lepra: estigma y prejuicio vivido por pacientes institucionalizados en Santa Catarina, Brasil (1940-1960)

\author{
Miriam Süssking Borenstein', Maria Itayra Padilha', Eliani Costa', \\ Vitória Regina Petters Gregório', Ana Maria Espíndola Koerich', Dorotéa Löes Ribas' \\ 'Universidade Federal de Santa Catarina. Departamento de Enfermagem. \\ Grupo de Estudos de História do Conhecimento da Enfermagem. Florianópolis, SC
}

Submissão: 25/08/2008

Aprovação: 10/10/2008

\section{RESUMO}

Trata-se de uma pesquisa Qualitativa com abordagem sócio-histórica cujo objetivo foi conhecer o estigma e preconceito vivenciado por pacientes/residentes institucionalizados acometidos pela hanseníase. Para tanto, foram entrevistados três pacientes que viveram em um hospital colônia no período do estudo, utilizando-se o método de história oral. Os dados foram coletados e posteriormente analisados, utilizando-se do referencial de estigma. Os resultados evidenciaram Que após o ingresso na instituição, esses doentes tiveram seus laços familiares rompidos, perderam seus direitos como cidadãos, em decorrência dessa situação, assumiram novas vidas em um novo contexto. Concluindo, o isolamento nosocomial por um longo período de tempo (anos de internação e afastamento), provocou a morte simbólica de muitos pacientes Que viviam com a esperança de um retorno ao convívio familiar e/ou social.

Descritores: Hanseníase; Preconceito; História; Institucionalização; Enfermagem.

ABSTRACT
This study is a Qualitative research with a socio-historic approach whose objective was to know the prejudice and stigma lived by the institutionalized patients/residents with hanseniase. To achieve this goal, three patients were intervewed who lived in a colony hospital during the research period, utilizing the oral history method. Data were collected and were further analysed, utilizing the stigma referencial. The results indicated that after the entry in the institution, these patients got their family bonds broken, lost their rights as citizens, regarding the situation, they took upon a new life, in a new environment. Concluding that, the nosocomial isolation for a long period of time (years of confinement and dismissal), caused the symbolic death of many patients that lived with the hope to cohabit with family and/or society.

Descriptors: Leprosy; Prejudice; History; Institutionalization; Nursing.

\section{RESUMEN}

El presente es un estudio de investigación cualitativa con abordaje socio-histórica. Tuvo como objetivo conocer el estigma y el prejuicio vivido por los pacientes institucionalizados portadores de lepra. Utilizándose el método de história oral, fueran entrevistados tres pacientes, Que vivieron en un hospital en el período del estudio. Los datos fueran colectados y después analizados utilizándose el referencial del estigma. Los resultados colocaran en evidencia Que, después del ingreso en la instituición, las personas tuvieran sus lazos familiares rotos, perdieran sus derechos como ciudadanos y asumiran nuevas vidas en un nuevo contexto. En conclusión, el aislamiento nosocomial por uno largo período de tiempo (años de internación y aislamiento), provocó la muerte simbólica de muchos Que vivian con la esperanza del regreso a la convívencia familial y social.

Descriptores: Lepra; Prejuicio; Historia; Institucionalización; Enfermería. 


\section{INTRODUÇÃO}

A milenar doença hanseníase, denominada durante muitos séculos por lepra, ainda traz contemporaneamente arraigada ao seu nome, o preconceito e discriminação daQueles que a desenvolveram ${ }^{(1)}$. Esta situação é originada basicamente em função da generalizada falta de informação por parte da população ao seu respeito.

O Brasil hoje é o segundo país em número absoluto de casos de Hansenlase, apresentando uma taxa de prevalência de 1.5 casos/ 10.000 habitantes, ficando apenas atrás da Índia, posição lastimável, considerando Que esta doença há muito tempo encontra-se erradicada nos países do primeiro mundo ${ }^{(2,3)}$. Atualmente as pessoas acometidas pela doença, não necessitam mais de internação, porém no passado em conseqüência da inexistência de medicamentos eficazes, era imprescindível Que o fizessem. No momento em Que eram diagnosticados como "leprosas", costumavam ser encaminhados para grandes instituições, longe das cidades, de onde praticamente nunca mais sairiam, eram os chamados "leprosários"(1,4,5).

Estas instituições foram responsáveis por um tratamento excludente ao longo dos séculos, e acarretaram como conseqüência a produção de uma imagem de "horror à doença", tendo como conseqüência um profundo estigma social ao simples contato com o doente, uma vez Que este, apresentava em geral, lesões ulcerantes na pele, e deformidades nas extremidades. Esta desfiguração do "leproso", provocou horror ao doente, a doença, e até mesmo, aos seus familiares ${ }^{(1)}$.

A sustentação científica para isolamento como forma de cuidado é datada do século XIX, Quando em 1897, na Primeira Conferência Internacional de Leprologia, realizada em Berlim, o médico Gerard Amauer Hansen, propôs o isolamento como medida fundamental. Até então, não se sabia como a doença era transmitida. Este médico/ pesquisador realizou inúmeros estudos entre 1870 a 1874. Em um destes, ao examinar as células leprosas encontradas nos nódulos formados na pele de um doente, percebeu a presença de pequenos bastonetes, Que era a forma como o bacilo se apresenta, Quando visualizado no microscópio. A partir de então, concluiu Que a doença era transmitida por um agente infeccioso e não por hereditariedade, muito menos por miasmas. Em 1923, no Terceiro Congresso Internacional de Leprologia na França, o isolamento começou a ser Questionado de maneira bastante tímida, uma vez Que o número de casos não diminuía ${ }^{(1)}$.

No Brasil, a política de controle da doença após a década de 30, era sobretudo com a construção de leprosários nas diversas unidades da federação, havendo estados em Que haviam mais de um, como São Paulo e Minas Gerais. Em Santa Catarina, mais precisamente em 1917, o Dr. Ferreira Lima, então Diretor de Higiene do Estado, obteve por meio de inquérito, informação de Que havia 62 morféticos (hansenianos) em doze municípios, dentre as Quais Florianópolis, São Francisco e Itajaí(6).

Em 1925, estimava-se em 250 o total de leprosos no Estado. Em 1927, o Dr. Carlos Corrêa, então Diretor de Higiene, afirmava Que este número havia aumentado para 400 em Santa Catarina. Em conseeüência dessa situação, resolveu escrever ao Dr. Heráclides César de Souza Araújo (um dos mais conceituados leprologistas de sua geração e pesquisador do Institudo Oswaldo Cruz) solicitando informações e sugestões para implantação de uma Colônia destinada a internação compulsória de doentes acometidos pela lepra, informando ainda, Que o estado possuía uma restrita verba para essa finalidade $^{(7)}$. Na carta, o diretor justificava a necessidade da construção do estabelecimento com as seguintes informações: "Trata-se de preencher os fins a Que se destina: o segregamento de doentes, com o seu tratamento e observação dos suspeitos, dando-lhes ao mesmo tempo o conforto Que nem sempre tem, e si possível, facultando-lhes um trabalho, Que possa ser útil a si próprio e ao estabelecimento, saúde e fraternidade"(6).

O Dr. Heráclides de Araújo, em resposta a carta enviada, Questionou a possibilidade de haver disponibilidade no Estado de uma ilha marítima de fácil acesso, com água potável e terreno fértil”, área isolada Que pudesse servir aos doentes internados, como uma colônia agrícola, segundo indicação da Sociedade Internacional de Leprologia, à época. Encaminhou em anexo, uma possível planta física Que continha um pavilhão, com dez Quartos individuais e também fotografias, Que possibilitava a visualização de como deveriam ser as casas, inclusive com sugestões para barateá-las, conforme modelo do Leprosário de Carville, em Lousianna, Estados Unidos ${ }^{(6)}$.

Além das sugestões feitas na época, o Dr. Heráclides Souza de Araújo, encaminhou carta ao Governador Adolfo Konder, em 1927. fazendo as seguintes recomendações: Fundação de uma colônia Agrícola para os morféticos, exame clínico e bacteriológico para as crianças nas escolas e seus professores uma vez ao ano, vacinação dos leprosos pela Rowlterapia (BCG intradérmica) e proibição de casamento dos leprosos. Com essas recomendações, deu-se início em 1937, a construção da Colônia santa Teresa no distrito de São Pedro de Alcântara, no município de são José, a 40 Km da capital. Tratava-se de uma fazenda, cercada por montanhas e mata ao fundo, tendo à frente, o Rio Maruim ${ }^{(6)}$.

A política do Governo federal de sanear o meio ambiente, foi incorporada pelo Governo Estadual e neste sentido, era necessário normatizar a sociedade, restringindo os comportamentos imprevisíveis e indesejáveis. A presença dos loucos, velhos, mendigos, prostitutas, desordeiros nas ruas e principalmente dos leprosos, ameaçava a nova ordem social Que se instalava. Nesse contexto foram criadas na Grande Florianópolis (Florianópolis, São José e São Pedro de Alcântara) diversas instituições de saúde destinadas "a cuidar" dos doentes psiQuiátricos, dos acometidos pelas doenças infecto-contagiosas e daqueles portadores de hanseníase.

Estes últimos, provavelmente, eram os Que mais provocavam repulsa à sociedade catarinense, por serem portadores de uma doença Que levava à deformidade física e por esse motivo, deveriam ser encarcerados em locais distantes e com contatos restritos com o mundo considerado "sadio". Para estes foi construído um hospital distante da capital catarinense, cerca de $40 \mathrm{~km}$ de Florianópolis, denominada inicialmente de Colônia Santa Teresa (CST) e posteriormente de Hospital Colônia Santa Teresa (HCST).

Este hospital caracterizou - se por seu um mundo à parte, distante de tudo e de todos. Os doentes que para lá foram enviados/ encaminhados, passaram a conviver em uma realidade construída específica para Que satisfizessem suas necessidades e vivessem os restos de seus dias, nessa instituição. O HCST foi considerado como um marco na história da hanseníase no Estado. Muito pouco tem sido escrito a respeito das instituições hospitalares catarinenses, e em decorrência disso, o Grupo de Estudos de História do Conhecimento da Enfermagem (GEHCE) criado em 1995, vinculado ao Departamento de Enfermagem da Universidade Federal de Santa Catarina (UFSC), vem através de um Projeto financiado pelo CNPQ, pesQuisando a história da enfermagem nos hospitais em Santa Catarina. 
Estes estudos justificam-se porque nessas primeiras instituições, foram criados os primeiros núcleos de enfermagem, os primeiros "serviços organizados”. Além de pesquisar como se caracterizava a enfermagem nessas instituições, o GEHCE entende Que não há como desvincular a profissão, do conhecimento acerca dos doentes, das doenças, dos cuidados, dos tratamentos efetuados, e por Que não dizer, da cultura relativa à saúde/doença de cada época. Por esse motivo, a importância de conhecer uma época impregnada de preconceitos e estigma ${ }^{a}$ para com os doentes acometidos pela hanseníase, ou mais precisamente "dos leprosos ou morphéticos", institucionalizado em um hospital, denominado por nós de "exclusão!" ${ }^{(8)}$. A Colônia Santa Teresa faz parte desse estudo, pois incorpora muitas das Questões Que não são conhecidas, como por exemplo, como os pacientes vivenciavam as Questões relativas ao estigma e preconceito. Estes sentimentos se davam em várias situações do cotidiano junto à família, emprego, comunidade, entre outros.

Este estudo tem como objetivo conhecer o estigma e o preconceito vivenciado por ex pacientes/residentes no HCST, no período de 1940 a 1960. O marco de início, ocorre Quando da inauguração do hospital, Quando passam a ser internados os primeiros pacientes; e 1960, em decorrência, de uma nova lei Que vinha sendo pensada, e posteriormente foi decretada ${ }^{(9)}$, Que possibilitou, aos doentes acometidos pela hanseníase, não ficarem compulsoriamente internados.

\section{METODOLOGIA}

Trata-se de uma pesquisa Qualitativa, de natureza sócio-histórica. Para tanto, foram entrevistados três ex-pacientes Que viveram no Hospital Colônia Santa Teresa em São Pedro de Alcântara/SC, no período compreendido entre 1940 a 1960. Os dados foram coletados através de entrevistas semi-estruturadas, utilizando-se do método de história oral. Foram utilizadas também, outras fontes documentais como: prontuários, relatórios da instituição e do governo estadual, artigos de jornais, artigos de revistas, dissertações de mestrado, teses de doutorado, entre outros. O desenvolvimento do estudo obedeceu as diretrizes estabelecidas ${ }^{(10)}$ e foi aprovado pelo Comitê de Ética da Universidade Federal de Santa Catarina (UFSC) (Parecer no. 149/2001). Além dos aspectos relacionados, os participantes foram orientados sobre o objetivo do estudo, da importância de sua participação e do direito ou não de participar da mesma. Todos os entrevistados permitiram Que seus nomes fossem expressos na pesquisa e assinaram o Termo de Consentimento Livre e Esclarecido. Os dados foram analisados utllizando-se como referencial teórico, os conteúdos referentes ao esttigma ${ }^{(8)}$, e categorizadodos a partir da técnica de conteúdo ${ }^{(11)}$.

\section{RESULTADOS E DISCUSSÃO}

\section{Colônia Santa Teresa}

Em I I de março de 1949, foi inaugurada a Colônia Santa Teresa,

\footnotetext{
${ }^{a}$ Estigma caracteriza-se por um atributo Que torna a pessoa diferente de outras, uma espécie de menos desejável, num caso extremo, uma pessoa completamente má, perigosa ou fraca, Pode ser deixada de ser considerada uma pessoa comum, para transformá-la em uma pessoa estragada e diminuída. Tal característica é um estigma, Quando o descrédito é muito grande. Algumas vezes pode ser considerado um defeito, uma fraqueza, uma discrepância entre a identidade social virtual e a identidade social real.
}

exclusivamente para internação de portadores de hanseníase de todo o Estado de Santa Catarina. No cerimonial de inauguração, estavam presentes Getúlio Vargas (Presidente da República), Nereu Ramos (interventor Federal do Estado de Santa Catarina), Adalberto Tolentino de Carvalho ( $l^{\circ}$. Diretor da Colônia Santa Teresa), diretoras da Federação da Sociedade de Assistência aos Lázaros, autoridades civis e militares e demais membros da sociedade. Foi um marco importante para a saúde no Estado, motivo de muitas fotos, amplo álbum de fotografias e notas nos jornais da época, ainda existentes na instituição(5).

O Hospital foi construído como uma pequena vila, constituída por casas padronizadas, destinadas a: residências para os casados (tipo casa geminada); pavilhões (tipo Carville) para o alojamento dos solteiros e pavilhão para as crianças. Além disso, havia prefeitura, delegacia de polícia e cadeia, teatro, cinema, emissora de rádio, refeitório geral, pavilhão médico, estação de fossa sanitária, garagem, grupo escolar, alfaiataria, oficinas, olaria pocilga, engenho de farinha, igreja, cartório, pavilhão de esportes, casa de expurgo para os recém ingressos, caixa beneficente, agência de correio e forno para incineração do lixo. Havia ainda, um local denominado de parlatório fechado (unidade que possuía dois ambientes, separado por um vidro, destinado aos encontros dos pacientes com suas raras visitas, dentre os Quais parentes e amigos).

Seguindo rigidamente os padrões estabelecidos de segregamento dos doentes, foram criadas duas áreas: uma destinada às residências dos funcionários, chamada "área limpa" ou "zona intermediária", Que ficava separada por um muro da "área suja" (enfermarias) ou "zona doente". Na primeira, encontrava-se a vila dos funcionários, casas das religiosas, residência do capelão, casa da administração e do médico diretor da instituição. A "zona suja" recebia todos os doentes, e dentro desta, coexistia uma "terceira zona", destinada ao tratamento dos casos mais graves, de doentes portadores de formas mais avançadas da hanseníase, com lesões e mutilações irrecuperáveis, conhecida pelos internos como "ferro velho". Observa-se aqui um preconceito entre os próprios doentes, Quando estes denominavam seus próprios companheiros pejorativamente. A fim de restringir os contatos com o mundo externo, havia dentro da instituição um comércio Que se utilizava de moeda própria ( 100 , 200, 300, 400, 500 e 1000 réis), seguindo a idéia, de Que se os leprosos "manuseassem o dinheiro normal", a doença espalhar-seia mais facilmente.

O tratamento era basicamente constituído por óleo de Chamulmoogra, Que podia ser em aplicação tópica, ingestão oral ou injetável. Os cuidados eram ministrados pelas religiosas Franciscanas, alguns funcionários e os próprios pacientes, Que ministravam cuidados de higiene e conforto aos doentes mais graves. Estes costumavam receber treinamento das irmãs. Quanto aos médicos, durante o período do estudo, havia alguns, um em particular foi o Dr. Adalberto Tolentino de Carvalho, Que além das funções de diretor, assumiu o tratamento dos doentes ${ }^{(6)}$ e o Dr. Ernani Polydoro São Thiago e Dr. Homero de Miranda Gomes ${ }^{b}$.

\footnotetext{
${ }^{b}$ Borenstein MS, Moreira AR, entrevistadoras. Landolina da Silva [entrevistada]. Florianópolis: GEHCE; 2003 jun 3. 2 fitas cassete (I 20 min.) Entrevista concedida ao acervo do Grupo de Estudos de História do Conhecimento de Enfermagem, Florianópolis: GEHCE/UFSC.
} 
Estigma e Preconceito Vivenciados pelos Pacientes

Um dos mais conhecidos autores ${ }^{(8)}$, Que estudou o estigma, referiu existirem três diferentes tipos: o primeiro, estaria relacionado com as abominações do corpo - ou seja, as deformidades físicas; o segundo, relativo às culpas de caráter individual, percebidas como vontade fraca, paixões tirânicas ou não naturais, crenças falsas e rígidas, desonestidades, decorrentes de distúrbios mentais, alcoolismo, homossexualismo, desemprego, comportamento político radical, entre outros. E finalmente, o terceiro tipo de estigma, está relacionado com às tribos, raças, nação e religião, Que podem ser transmitidos através da linhagem e contaminar por igual, à todos os membros de uma mesma família. Em última análise, todos esses tipos de estigma, convergem para uma característica comum, ou seja, de um indivíduo Que na relação social com os demais, possui um traço Que pode se impor a uma atenção especial, e Que em geral, afasta aqueles que encontra, destruindo a possibilidade de atenção positiva para si. Este indivíduo possui um estigma. Na hanseníase, o estigma está diretamente vinculado com as Questões relativas ao corpo, a imagem, em geral, o indivíduo pode apresentar desde manchas e/ou lesões de variados tipos, e até mesmo, deformidades físicas por comprometer o sistema nervoso periférico.

Ao entrevistarmos os pacientes Que haviam sido internos na Colônia Santa Teresa, estes em vários momentos, descreveram como se sentiram estigmatizados pela sociedade. É interessante observar, Que estas manifestações de rejeição, estigma e exclusão, se deram nos mais variados espaços e situações, desde os nú-cleos familiares, e até mesmo, no espaço interno institucional, como podemos visualizar a seguir.

\section{O Estigma no Domicílio}

Até 1940, Quando não haviam instituições hospitalares para acolher os doentes acometidos pela hanseníase em Santa Catarina, estes permaneciam em suas residências, juntos de suas famílias. As famílias costumavam construir peeuenas casas, ou Quartos separados, onde estes pudessem permanecer. Os doentes recebiam as refeições, roupas, medicação entre outros, de modo Que não saíssem do seu espaço, e colocassem em risco, os demais familiares e as pessoas da comunidade.

"Olha eu ficava em uma casa isolada, eu nem saía mais de casa, porque naquela época, em 1940, o pessoal tinha um medo maluco, né. Quando vinha gente lá na casa dos meus pais, eu fechava a janela da minha casa e já me escondia"(13).

Se dentro das residências, os familiares já apresentavam problemas no tratamento e aceitação das pessoas acometidas pela doença, a situação piorava ainda mais, Quando se tratava no espaço do trabalho.

\section{O Estigma no Trabalho}

Ao recordar o passado, muito comovida referiu ter vivenciado a seguinte situação junto com seu irmão, Que era funcionário do Porto de Imbituba/SC, e que na época, ainda não apresentava nenhuma manifestação da doença ${ }^{c}$. Portanto, não tinha a menor idéia de ser

c Borenstein MS, Moreira AR, entrevistadoras. Adília Ferraz [entrevistada]. Florianópolis: GEHCE; 2003 jul 3.2 fitas cassete (I 20 min.) Entrevista concedida ao acervo do Grupo de Estudos de História do Conhecimento de Enfermagem, Florianópolis: GEHCE/UFSC. portador da hanseníase.

"Sem sinais aparentes da doença, meu irmão foi diagnosticado no trabalho, no Porto de Imbituba. Na mesma hora, foi afastado da empresa, que naquela época era assim, dizia que era doente e pronto, já tinha Que ser afastado do serviço. Quando meu irmão ficou sabendo, ele não acreditou, sentou num banco e desmoronou, não acreditava. Então nós viemos juntos de ambulância, em maio de $1947^{\prime \prime(13) . ~}$

\section{O Estigma na Colônia Santa Teresa}

Mesmo internados em Santa Teresa, e portanto, sendo todos, portadores da hanseníase/lepra, havia diferenças entre aqueles que ainda não apresentavam sinais evidentes da doença, daQueles que já tinham lesões leprosas e deformidades graves. Estes últimos, eram tratados com muitas diferenças, ainda mais estigmatizados, chamados pejorativamente de "ferro velho". Os hansenianos mais prejudicados, ficavam em enfermarias isoladas do hospital, mais restritas, sendo cuidados por outros doentes Que se apresentavam em condições melhores e que se dispunham à ajudar. Até porQue, em várias falas dos entrevistados, estes referiram Que as irmãs Que atuavam na enfermagem, ficavam mais, na administração do cuidado, e no treinamento dos poucos funcionários e pacientes, assumindo os grandes curativos e auxiliando nas pequenas cirurgias.

$\mathrm{Na}$ Colônia Santa Teresa, não havia controle da natalidade, portanto era bastante comum Que as mulheres tivessem seus filhos na instituição, tanto decorrentes de casamentos anteriores, Quando internavam com seus cônjuges, como decorrentes de casamentos realizados na própria instituição. Nesses casos, as irmãs eram Quem faziam os partos. Essas crianças assim Que nasciam, eram encaminhadas imediatamente para o Educandário, há $20 \mathrm{~km}$ do hospital, de tal modo Que não fossem contaminadas.

$\mathrm{Na}$ época, o modelo de tratamento chamado "tripé", era constituído pelo leprosário, preventório e dispensário. No leprosário ficavam internados, aqueles Que já tinham o diagnóstico comprovado. Os filhos Que nasciam na instituição, eram encaminhados imediatamente após o nascimento para os preventórios, de forma à evitar o contato com os pais doentes. E finalmente, os dispensários, foram criados com o objetivo de prevenir casos futuros daqueles que conviveram com os doentes, também chamados, de comunicantes Segundo alguns estudiosos ${ }^{(1)}$, o combate contra a Hanseníase era difícil, pois para cada caso notificado e internado em estado avançado, o doente deixava um rastro de Quatro a seis doentes no caminho, isso dificultava a extinção da doença. Essas situações conseguiam aumentar ainda mais, o estigma dos doentes e seus familiares, Que acabavam na esteira, também sendo excluídos e estigmatizados.

Ao rememorar sua vida na instituição, um paciente lembra de um fato que o deixou bastante triste ${ }^{d}$. Foi Quando fez parte da equipe Que restaurou a antiga Administração e descobriu muitas caixas, contendo um grande número de cartas, inclusive suas, Que não foram enviadas aos familiares. A administração entendia Que estas cartas poderiam contaminar as pessoas. Do mesmo modo, o dinheiro dos

\footnotetext{
${ }^{d}$ Borenstein MS, Moreira AR, entrevistadoras. André Santos Ferraz [entrevistado]. Florianópolis: GEHCE; 2003 jul 3. 2 fitas cassete (I 20 min.) Entrevista concedida ao acervo do Grupo de Estudos de História do Conhecimento de Enfermagem, Florianópolis: GEHCE/UFSC.
} 
pacientes era envolvido em papel, de modo à "não contaminar" Quem o tocasse, Quando um dos funcionários fazia compras para estes fora do Hospital. É importante ressaltar Que a transmissão da doença se faz através das vias aéreas superiores, e a maioria das pessoas destrói o bacilo e não adoece, por possuir imunidade natural, o Que em geral as pessoas não sabiam, e até hoje a maioria desconhece ${ }^{(1)}$.

Se dentro da instituição havia o estigma de alguns em detrimento de outros, Quando os doentes resolviam visitar os familiares passavam grande trabalho como pode-se verificar a seguir.

\section{O Estigma na Sociedade}

Não era comum, mas muitos doentes costumavam sair do hospital por motivos diversos, inclusive para visitar a família. Nesses momentos sofriam todo o tipo de discriminação, como pode ser visualizado a seguir:

"Nossa família sempre receberam muito bem, ali dentro, ninguém tinha medo de ninguém, todo mundo era um. Mas na volta, Quando a gente ia pegar um ônibus, a gente era barrado no ônibus, o motorista não pegava a gente. Aí a gente vinha a pé até a Colônia Sant'Ana. Uma mulher deu pouso pra nós, a senhora que deu pouso, disse que o esposo dela era internado também, e ela disse: vocês sai de madrugada daQui, para Que o povo não veja.
Deus o livre se eles sabem Que um tenho marido lá"(13).

A partir destas falas, é possível perceber nitidamente, o preconceito, o estigma e a discriminação das pessoas que eram acometidas pela hanseníase e o duplo sofrimento pelo Qual passavam.

\section{CONSIDERAÇÕES FINAIS}

Através deste estudo, percebe-se Que o emprego de uma política pública autoritária, implementadas no país, a partir de década de 30 , com a internação compulsória de doentes acometidos pela hanseníase, repercutiu gravemente na vida dessas pessoas. Muitos perderam suas famílias, seus empregos e até mesmo suas identidades no contexto onde viviam Tiveram Que enfrentar uma nova vida, restrita e reclusa, procurando uma adaptação.

Para alguns, o asilo não representou a morte social, pois conseguiram constituir novas famílias, inclusive tendo filhos e procuraram desenvolver um papel naQuele meio, até mesmo na função de "enfermeiros", e outras atividades Que a instituição proporcionava. Entretanto para uma grande maioria, o isolamento nosocomial por longo período de tempo (anos de internação e afastamento), provocou a morte simbólica de muitos Que viviam a esperança de um retorno ao convívio familiar e/ou social.

\section{REFERÊNCIAS}

1. Maciel LR. A solução de um mal Que é um flagelo: notas históricas sobre hanseníase no Brasil do século XX. In: Nascimento DR, Carvalho DM. Uma história Brasileira das doenças. Brasília: Paralelo 15; 2004.

2. Lana FCF, Amaral EP, Lanza FM, Lima PL, Carvalho ACN, Diniz LG. Hanseníase em menores de 15 anos no Vale do Jequintinhonha, Minas Gerais, Brasil. Rev Bras Enferm 2007; 60(6): 696-700.

3. Ministério da Saúde (BR). Hanseníase. Brasília: Ministério da Saúde. [citado em: 08 mar 2008]. Disponível em: http:// portal.saúde.gov.br/portal/saúde/visualizar texto.cfm? idtxt $=27445$

4. Foucault M. História da loucura. São Paulo: Perspectiva; 1995.

5. Borenstein MS, Ribeiro AAA, Moreira AR, Velho JAS. Hospital Colônia Santa Teresa: o cotidiano dos pacientes institucionalizados no sul do Brasil (1940-1960). Temperamentum 2005; 2. [citado em: I I jan 2006]. Disponível em: http://www.index-f.com/temperamentum/tn2/t0 I 33.php

6. Araújo, HCS. A história da lepra no Brasil. Rio de Janeiro: Imprensa Nacional; 1956.

7. São Thiago PEI. A medicina Que aprendi, exerci e ensinei. Florianópolis: UFSC; 1996.

8. Goffman E. Estigma: notas sobre a manipulação da identidade deteriorada. Rio de Janeiro: Zahar; 1982.

9. Brasil. Decreto no. 968, de 7 de maio de 1962. Baixa normas técnicas especiais para o combate à Lepra no país e dá outras providências. Diário Oficial [da] República Federativa do Brasil 1962 mai; :5 I13-5 II4.

10. Ministério da Saúde (BR). Conselho Nacional de Saúde. Resolução no. 196, de 10 de outubro de 1996. Dispões sobre diretrizes e normas regulamentadoras de pesQuisas envolvendo seres humanos. Bioética 1996; 4(suppl 2): 15-25.

11. Bardin, L. Análise de Conteúdo. Lisboa: Edições 70; 2004. 